\title{
Computer control of anticoagulant dose for therapeutic management
}

\author{
P J Ryan, M Gilbert, P E Rose
}

\begin{abstract}
Objective-To improve the standard of managing anticoagulant treatment and provide a basis for therapeutic quality control.

Design-Implementation of a comprehensive computerised system for decision support.

Setting-Three anticoagulation clinics in South Warwickshire.

Subjects-Patients in South Warwickshire receiving anticoagulant treatment from September 1988 to March 1989.

Main outcome measure-International normalised ratio was measured and recorded at each visit.

Results-688 Patients' visits were analysed statistically, and a $38 \%$ improvement was achieved in the results of international normalised ratios falling within the recommended therapeutic ranges of the British Society for Haematology.

Conclusions - The implementation of a computerised anticoagulation support system resulted in better management of patients. The system provides a basis for uniform management of treatment and a common platform for national or international trials.
\end{abstract}

\section{Department of Haematology, South Warwickshire Hospital, Warwick CX34 5BW $\mathrm{PJ}$ Ryan, MB, senior house officer}

Coventry Technical College, Coventry $M$ Gilbert, lecturer in computer applications

Correspondence and requests for reprints to: Dr Rose.

$\operatorname{BrMed} \mathcal{f} 1989 ; 299: 1207-9$
P E Rose, MRCP, consultant

\section{Introduction}

We have developed a computer program for anticoagulation treatment to provide accurate reproducible control of warfarin dose in our clinics. The system runs on the latest IBM-compatible portable personal computer. While previous attempts have been made to use computer assisted dosage in anticoagulant clinics, ${ }^{12}$ no system to date has been written that recommends a dose and period of recall in accordance with the clinical categories laid down in the recommendations of the British Society for Haematology for
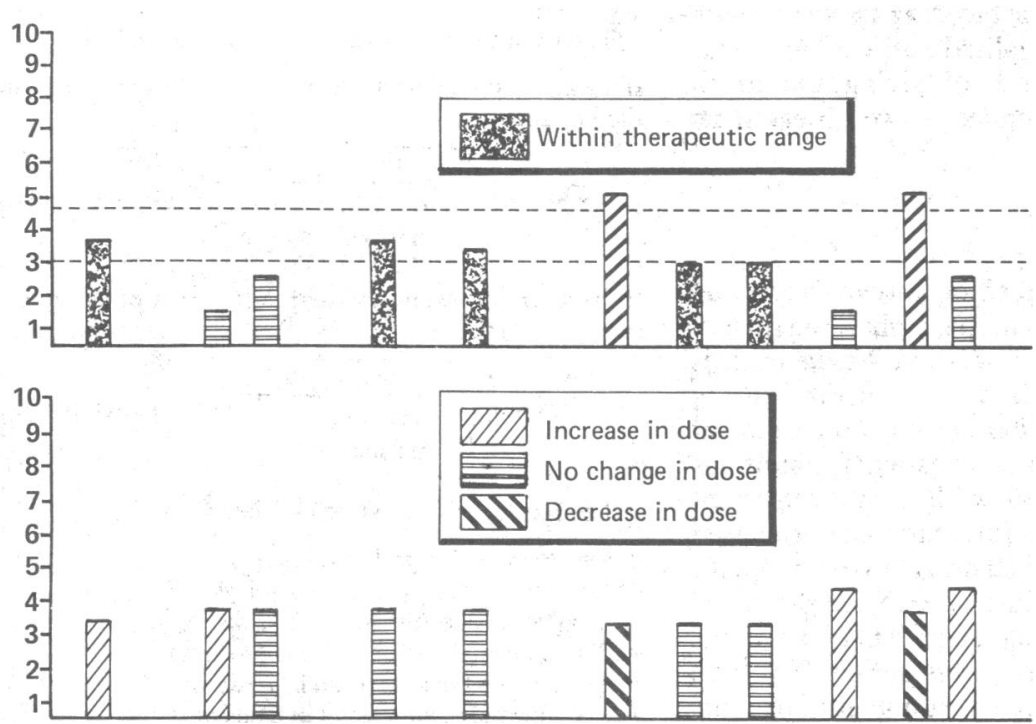

Top: Results of tests for international normalised ratios for 52 week period. Bottom: corresponding warfarin doses over same period anticoagulant control. ${ }^{3}$ Successful treatment depends on skill in dosage and effective laboratory quality control. ${ }^{4}$ While great efforts are being made to ensure standardisation of techniques and calibration of reagents, ${ }^{5-7}$ little has been done to ensure the clinician is consistent and properly trained in control of warfarin treatment. Also little has been done to audit the medical consequences of treatment.

A second component of our anticoagulant management support system provides full clerical support, including clinic and ambulance lists and letters to general practitioners on starting and stopping treatment. The third component of the system provides clinical audit of treatment. This is an essential prerequisite to therapeutic quality control. ${ }^{38}$

\section{Methods}

In South Warwickshire there are 400 patients receiving oral anticoagulant treatment, who visit one of three clinics on different sites. On each clinic day the computer is taken to the consultation room. After the user enters an identity and password the program starts. The international normalised ratio is measured by a capillary method and recorded on the patient's record card. Information on the patient can be shown by entering his or her name or hospital number. After the international normalised ratio is entered the computer produces bar charts showing previous international normalised ratios, the recommended therapeutic range, and the previous doses of warfarin for 52 weeks (figure) The computer then displays the therapeutic range (from the British Society for Haematology) for the patient's condition and the current dose of warfarin and a summary of stability over the previous five visits.

The computer recommends a dose of warfarin, gives the date of the next appointment, and, in the case of a high international normalised ratio, recommends a period of suspension of treatment. These three variables may be amended by the clinician if necessary. A suggested schedule indicating clinic appointments for the next three months is also provided. In addition, the main screen also displays the patient's current treatment and an area for free text, which is used to record important clinical events that may be relevant to treatment.

There is instant access to a database containing names of up to 200 interacting drugs. A warning is given to stop treatment if a recall date extends beyond the recommended period. If the international normalised ratio is greater than 4.5 the clinician is prompted by a list of possible haemorrhagic problems. Any problems of bleeding are considered in the final calculation of dose and may lead to suggestions for further action, such as giving fresh frozen plasma. There is also a facility to use the system to advise patients on dose by post and a facility for entering the patient's history.

Further details on the hardware and software may be 
TABLE I-Mean international normalised ratio and mean international normalised ratio plus or minus $1 S D$ for therapeutic range 3.0 to 4.5 for all patients attending anticoagulation clinic during 1 October 1988 to 31 March 1989

\begin{tabular}{lccc}
\hline $\begin{array}{l}\text { Month of } \\
\text { attendance }\end{array}$ & Mean minus 1 SD & Mean & Mean plus 1 SD \\
\hline Oct & 2.05 & 2.98 & 3.92 \\
Nov & $2 \cdot 15$ & 3.04 & 3.92 \\
Dec & $2 \cdot 18$ & 3.15 & $4 \cdot 12$ \\
Jan & 2.34 & 3.55 & 4.32 \\
Feb & 2.49 & 3.35 & 4.21 \\
Mar & 2.60 & 3.46 & 4.33
\end{tabular}

TABLE II - Proportion of patients whose international normalised ratio was below, above, or in therapeutic range 3.0 to 4.5 each month since introduction of anticoagulant management support system, 1 October 1988 to 31 March 1989

\begin{tabular}{lccrrrr}
\hline & Oct & Nov & Dec & Jan & \multicolumn{1}{c}{ Feb } & \multicolumn{1}{c}{ Mar } \\
\hline No (\%) below & $76(42 \cdot 5)$ & $118(47 \cdot 4)$ & $82(36 \cdot 0)$ & $76(34 \cdot 9)$ & $75(32 \cdot 6)$ & $62(25 \cdot 8)$ \\
No (\%) in range & $81(45 \cdot 3)$ & $109(43 \cdot 8)$ & $111(48 \cdot 7)$ & $113(51 \cdot 8)$ & $128(55 \cdot 7)$ & $151(62 \cdot 9)$ \\
No (\%) above & $22(12 \cdot 3)$ & $22(8 \cdot 8)$ & $35(15 \cdot 4)$ & $29(13 \cdot 3)$ & $27(11 \cdot 7)$ & $27(11 \cdot 3)$
\end{tabular}

obtained from PER. The method of calculating recommended dose is shown in the appendix.

\section{Results}

The international normalised ratios for six months showed a consistent improvement, with results shifting towards the median value of the range. Table I shows that for the range 3.0 to 4.5 the mean international normalised ratio rose from 2.98 to 3.46 , the values for plus and minus $1 \mathrm{SD}$ showing a parallel rise. Plus and minus 1 SD results in about $15 \%$ below range, $70 \%$ in range, and $15 \%$ above range in a normal Gaussian distribution. Table II shows that the number of patients within the range increased progressively from $45 \cdot 5 \%$ to $62.9 \%$ over the six months, indicating that the guidelines of the British Society for Haematology were not strictly applied before the introduction of the computer, probably because of concern about giving too much anticoagulant.

Of 688 visits recorded in the first three months of 1989,83 (12\%) international normalised ratios greater than 4.5 were seen, and $33(4.8 \%)$ patients had problems with bleeding (table III). Of these 33 patients, greater than $4 \cdot 5$. All the patients were managed either by a reduction in dose alone or combined with suspensions of warfarin for up to three days. No patients required fresh frozen plasma. Three patients reported gastrointestinal bleeding on five visits and on only one of these visits was the bleeding associated with a raised international normalised ratio of $4 \cdot 8$. Our results suggest that the fear of giving too much anticoagulant may be unfounded as we observed no serious bleeding event.

TABLE III - Problems with bleeding reported by patients receiving anticoagulation in 688 visits, 1 fanuary 1989 to 31 March 1989

\begin{tabular}{lc}
\hline Problem & $\begin{array}{c}\text { No of } \\
\text { patients }\end{array}$ \\
\hline
\end{tabular}

\begin{tabular}{lr}
\hline Epistaxis & 15 \\
Excessive bruising & 7 \\
Gastrointestinal bleeding & 5 \\
Haematuria & \\
Haemoptysis & 2 \\
$\begin{array}{l}\text { Menorrhagia } \\
\text { Oral mucosal bleeding }\end{array}$ & \\
Other & 4 \\
\hline Total & 33 \\
\hline
\end{tabular}

\section{Discussion}

With an increasing number of patients receiving anticoagulant treatment ${ }^{3}$ and more emphasis on quality control the need for computer assisted management is greater than ever. Our results indicate that during the period since introduction of the anticoagulant management support system, our patients' conditions have been better controlled with more consistent prescribing. Thus, the mean international normalised ratios have progressively moved nearer to the midpoint of the therapeutic range-that is, 3.75 for the range 3.0 to $4 \cdot 5$. Also, the number of patients within the range increased steadily during this period. This was achieved without an increase in the number of patients receiving too much anticoagulant and without risk of serious complications of bleeding. only 13 also had an international normalised ratio of

As we move nearer to better therapeutic quality control with the standardisation of laboratory methods we need to be equally diligent with clinical management. Previous studies have shown that control of anticoagulation is often far from perfect. Duxbury found that in 100 patients receiving short term anticoagulation for three months only half were adequately controlled for half of the time. ${ }^{4}$ Other studies have resulted in $12-85 \%$ of patients being adequately controlled, depending on the choice of therapeutic range. ${ }^{910}$

By using the guidelines of the British Society for Haematology information should now be comparable among centres. The system allows all relevant information to be collected without extra effort or inconvenience to patients, clinicians, or clerical staff. Furthermore, we have highlighted the fact that collaboration with referring doctors is necessary to improve advice given to new patients. We have found the system quickly enables junior staff to prescribe consistently with confidence and avoids too frequent recall of patients.

We suggest the following methods to establish the level of treatment: $(a)$ establish a set of guidelines that are medically desirable and technically achievable; (b) establish a method of collecting data on patients' treatment; $(c)$ monitor treatment against target (therapeutic quality control); (d) evaluate the results of treatment regarding the medical condition; and (c) adjust ( $a$ ) as appropriate.

The national external quality assessment scheme collected data on managing anticoagulation in the United Kingdom, and subsequently a set of guidelines was produced by the British Society for Haematology. ${ }^{3}$ This is the first step of the process as outlined above. The second step is the collection of data on patients' treatment, which our system is well designed to do. Thirdly, there is a need to compare the outcome of treatment with the given standard; without computerised data such a comparison is a laborious task. Information stored could be collected for national and international comparison. Multicentred trials of anticoagulant treatment are limited in their usefulness as there is no standardisation of management and subsequent retrieval of data. This problem was highlighted in the Medical Research Council's studies in the 1960s of anticoagulation treatment after myocardial infarction." When enough information has been collected appropriate analysis can be made to redefine the specific ranges if necessary.

\section{Appendix}

The recommended dose is calculated as follows.

If the international normalised ratio $>120 \%$ of target (mean of therapeutic range):

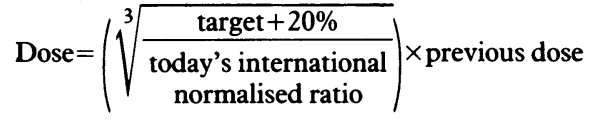

If the international normalised ratio $<80 \%$ of target (mean of therapeutic range):

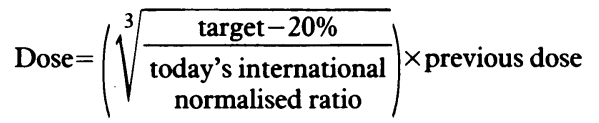

The recall period is based as follows:

- One normal result recall in 28 days

- Two normal results recall in 42 days

- Three normal results recall in 56 days

- Four normal results recall in 70 days

- Five normal results recall in 84 days days).
- One low result recall in 7/14 days

- One high result recall in $7 / 14$ days (stop treatment $1 / 2 / 3$ 
1 Wilson R, James AH. Computer assisted management of warfarin treatment. BrMed f 1984;289:422-4.

2 Wyld PJ, West D, Wilson TH. Computer dosing in anticoagulant clinics - the way forward? Clin Lab Haematol 1988;10:235-6.

3 British Society for Haematology. Guidelines on oral anticoagulation. London: British Society for Haematology, 1984. (Haemostasis and Thrombosis Task Force (BCSH) report to members.)

4 Duxbury BMcD. Therapeutic quality control leading to further clinical assessment of oral anticoagulation. Acta Haematol (Basel) 1986;76:65-7 5 Poller L. United Kingdom external quality assessment in blood anticoagulation: the first 21 years. $\mathcal{F}$ Clin Pathol 1989;42:1-3.

6 Poller L, Taberner DA, Thompson JM, Darby KV. Survey of prothrombin time in national external quality assessment scheme exercises (1980-7). f Clin Pathol 1988;41:361-4.
7 Poller L. INR and the therapeutic range. Biologia and Hematologica 1987;9: 203-13.

8 Duxbury $\mathrm{BMcD}$. Computers in anticoagulation clinics: standardization of computer programming. Clin Lab Haematol 1988;10:481-3.

9 Copplestone A, Roath S. Assessment of therapeutic of anticoagulation. Acta Haematol (Basel) 1984;71:376-80.

10 Majumdar G, Payne RW. Quality of anticoagulant therapy. Clin Lab Haematol 1986;8:79-80.

11 British Medical Research Council. An assessment of short term anticoagulant administration after cardiac infarction. Br Med $\mathcal{F}$ 1969;i:835-43.

(Accepted 25 August 1989)

\section{Reading binges}

\section{Nicholas E Davies}

If there is nothing to read in heaven, I am not sure I want to go.

\section{ARISTIDES (JOSEPH EPSTEIN),}

The American Scholar, 1989

In my practice of internal medicine in Atlanta, Georgia, I hear the problems and concerns of many people. Over the past 30 years they seem to have about them a remarkable sameness. A child is doing poorly in school, or worse, she is both single and pregnant, or worse yet, he is experimenting with drugs; a husband or a wife is drinking too much; an elderly parent living alone is causing great guilt in the daughter; a job is boring; a spouse is boring; life is boring. The problems are endless, the problems are ageless.

Should I visit my internist and should she ask me about which of my problems consumed the greatest amount of thought, I would be too embarrassed to answer. Indeed, I would probably lie. Yet the truth is that I spend an inordinate amount of time thinking about what I shall read during my summer vacation. It is a major concern. This immediately says several things. Firstly, it says that I do not have many serious problems, which is true. Secondly, it says that I must put great stock in reading, also true. Thirdly, it says that I must be some sort of reading nut, a bibliomaniac of sorts - a debatable topic in my family.

In an address to the Medical Library Association in Belfast in 1909, William Osler quoted Aristotle: "In the case of our habits we are only masters of the beginning, their growth by gradual stages being imperceptible, like the growth of a disease." Osler then added, "And so it is with the habit of reading, of which you are only master at the beginning - once acquired, you are its slave."'It has come to pass during the past 19 years that I have developed the wonderful habit of annual reading binges. Despite being an avid reader all my life, there are literally hundreds, perhaps thousands of books that I want to read but never seem to get around to. Therefore, each summer I reserve a week to acknowledge my bondage to reading and to indulge myself in the pleasure of becoming immersed in the world's great literature.

My affliction, if it can be called that, doubtlessly began in utero with the passage of some sort of neurotransmitter across the placenta into my brain's reading centre. The binges themselves began in childhood. My mother, a woman of unquestionable probity, swears that she read Lindberg the Lone Eagle to me over a thousand times. Reading was indelibly impressed on the DNA in my reading centre during my ninth year, when I had osteomyelitis and was bedridden for several months. Single books were not enough. My parents turned to series-Tom Swift, The Rover Boys, The Little Colonel, the Zane Gray books, and many others.
A marvellous English teacher in the eighth grade (my 13 th year) abetted my love of reading. She added one point to her students' final grade for each book they read and reviewed for her above the required 10 . When I had read 29 she declined to give me more than 99 (out of a possible 100). "No one is perfect," she noted acerbically. She approached it.

The reading required in college considerably blunted my reading sprees, yet I do recall having a few during summer holidays. One notable binge occurred at the age of 16, when I read War and Peace in three days, not bad for a slow reader. But I remember that particular binge not so much for reading a wonderful novel as for realising for the first time how much better it is to read a complex book in its entirety, at one sitting, rather than reading it spread out over several weeks.

Another well remembered binge occurred at the age of 19, just at the end of the second world war, on a liberty ship loaded with wheat sailing from Portland, Oregon, to Rouen. I was the purser/pharmacist mate on the SS Eli Whitney, going to sea (shipping out, as we said) for the first time. Except for opening the ship's store for an hour each day, I had little to do at sea but treat minor injuries as they occurred in our 42 man crew. Because I was reared in the mountains of Virginia my first week aboard ship was spent exploring the vessel and enjoying the beautiful Pacific Ocean. After passing through the Panama Canal we docked at Colón on the Atlantic side. Whereas now I would probably seek out an English language bookstore, I then joined my shipmates in a nearby bar and drank rum and cola to near oblivion, leaving me with a monumental hangover that I still remember. With little to do for the next two weeks en route to France, I read day and night, taking time out only to eat and to open the ship's store. By the 10th day I had devoured most of the ship's small collection of books. I especially remember The Scarlet Letter, Hawthorne's "somber romance of conscience, sin and concealed guilt" that was set in seventeenth century New England and Charles Reade's The Cloister and the Hearth, a convoluted novel about life in the late fifthteenth century that contains within it the apocryphal story of Erasmus's parentage. Unfortunately, my absence on deck prompted our Queeg-like captain, a former skipper of a garbage scow from San Francisco who had been pressed into sea duty during wartime, to inquire if I had fallen overboard. When told that I had spent my time reading in my cabin he called me to the bridge and in front of the mate and coxswain yelled in my face, "Goddamn it, purser, I want to see your goddamn ass on deck three times a goddamn day. Sailors don't spend their goddamn time reading goddamn books." Thus ended a notable binge. 